\title{
Dynamic Effect Analysis and Countermeasure Research on the Coordination of Economic Development and Industrial Exhaust Gas Emission
}

\author{
Hui Yu* \\ College of Science, Heilongjiang Bayi Agricultural University, Daqing 163319, \\ China \\ *Corresponding Author : yuhui163@163.com
}

\begin{abstract}
According to the measurement indexes of industrial emission and air quality in a certain area of China, with the help of regression model, SPSS software and MATLAB software, AQI index has significant relationship with PM10, PM2.5, NO2, SO2, Co, etc. Based on this, this paper analyzes the dialectical relationship between economic development and environmental protection, and gives corresponding countermeasures and suggestions.
\end{abstract}

KEYWORDS: Air quality; Industrial waste gas; AQI index; Countermeasure analysis

\section{Introduction}

Air quality has become a hot issue that people are increasingly concerned about. Real and effective air quality analysis plays an important role in guiding our production activities.

In 1994, the pollution heaven hypothesis in [1,2] was proposed for the NorthSouth trade model. In 2013, on the basis of the previous research, Carol, etc. (see [3]) have carried out an extended study to analyze cooperative and non cooperative trade and environmental policy related welfare concept, which integrates asymmetric information related to pollution reduction and management costs into a system. In [4,5], air pollution in China is studied.

At present, the air pollution in China is still very serious, mainly manifested as soot pollution. The concentration of total suspended particles in urban air environment generally exceeds the standard, so the pollution of sulfur dioxide is always at a high level, and the pollution of nitrogen oxide is increasing. Current situation of total emission of air pollutants: firstly, pollution caused by sulfur dioxide. With the rapid development of China's economy, coal consumption is increasing. The scope of acid rain pollution caused by sulfur dioxide emissions has been expanding, and now it has extended to most areas south of the Yangtze River

Published by Francis Academic Press, UK 
Academic Journal of Computing \& Information Science

ISSN 2616-5775 Vol. 3, Issue 1: 114-121, DOI: 10.25236/AJCIS.2020.030112

and east of the Qinghai Tibet Plateau. How to analyze the relationship between environmental pollution and economic development caused by industrial waste gas emission in theory and put forward solutions is a historical figure given to scientific researchers by the times.

Let's take this as a starting point for research.

\section{Effect analysis}

In this section, through data analysis, it shows that there is a correlation between air quality and industrial pollutants, and qualitatively expounds the dialectical relationship between environment and economic development.

\subsection{Industrial waste gas and environmental assessment}

Aiming at the air quality data of a certain area in China (see [6]), the first step is to use MATLAB software to carry out one-way regression analysis of $\mathrm{SO} 2, \mathrm{NO} 2$, $\mathrm{CO}$ and AQI. It is found that there is no obvious linear relationship between AQI and SO2, NO2, Co. Then we use SPSS software to do linear regression analysis on PM2.5 and AQI, and find that the linear relationship between PM2.5 and AQI is significant, and use MATLAB software to do linear regression analysis on PM2.5 and AQI, and find that the results are consistent with the results of SPSS analysis, so we can establish the AQI evaluation system is over dependent on PM2.5.

Then the relationship between PM10 and AQI is analyzed by the same method. Then, PM2.5 is given a weight of $0.7387, \mathrm{PM} 10$ is given a weight of 0.2140 , and the linear relationship between PM2.5, PM10 and AQI is made. As shown in the figure 1 below.

Published by Francis Academic Press, UK 
Academic Journal of Computing \& Information Science

ISSN 2616-5775 Vol. 3, Issue 1: 114-121, DOI: 10.25236/AJCIS.2020.030112

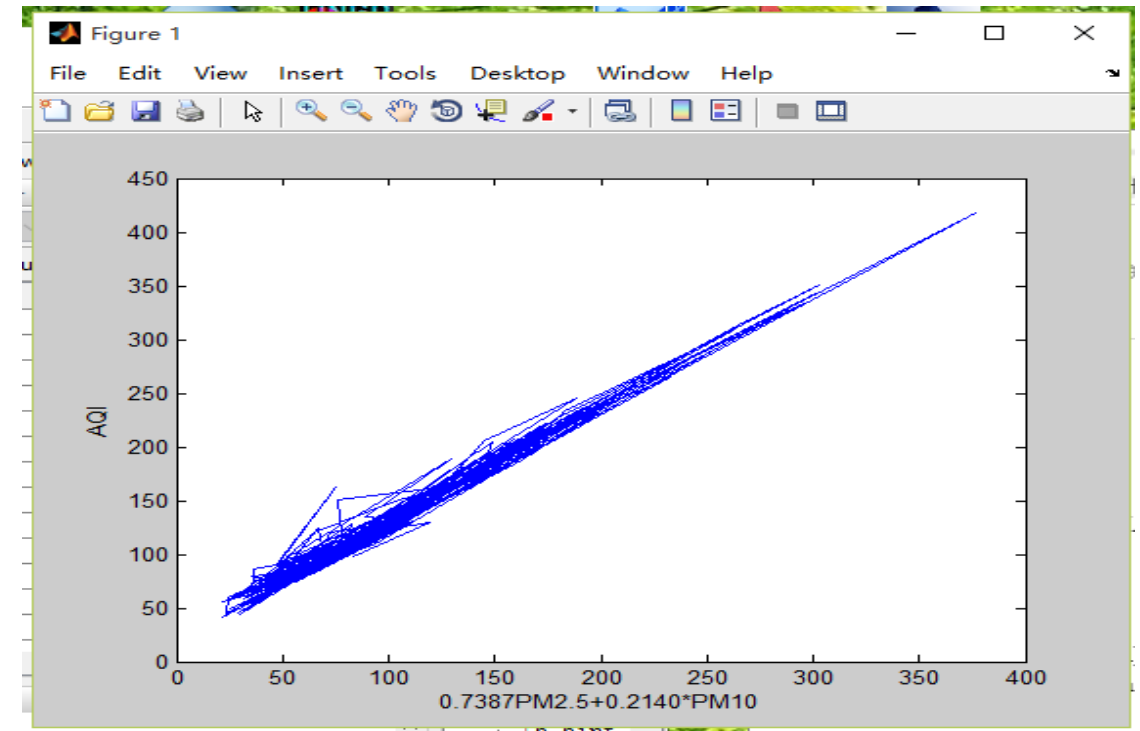

Figure 1. Relationship between PM2.5, PM10 and AQI

However, through the analysis of the residual and the confidence interval of the residual in the figure 2 , we can see that there are some abnormal points in the original data, indicating that there are still quantitative pollution factors.

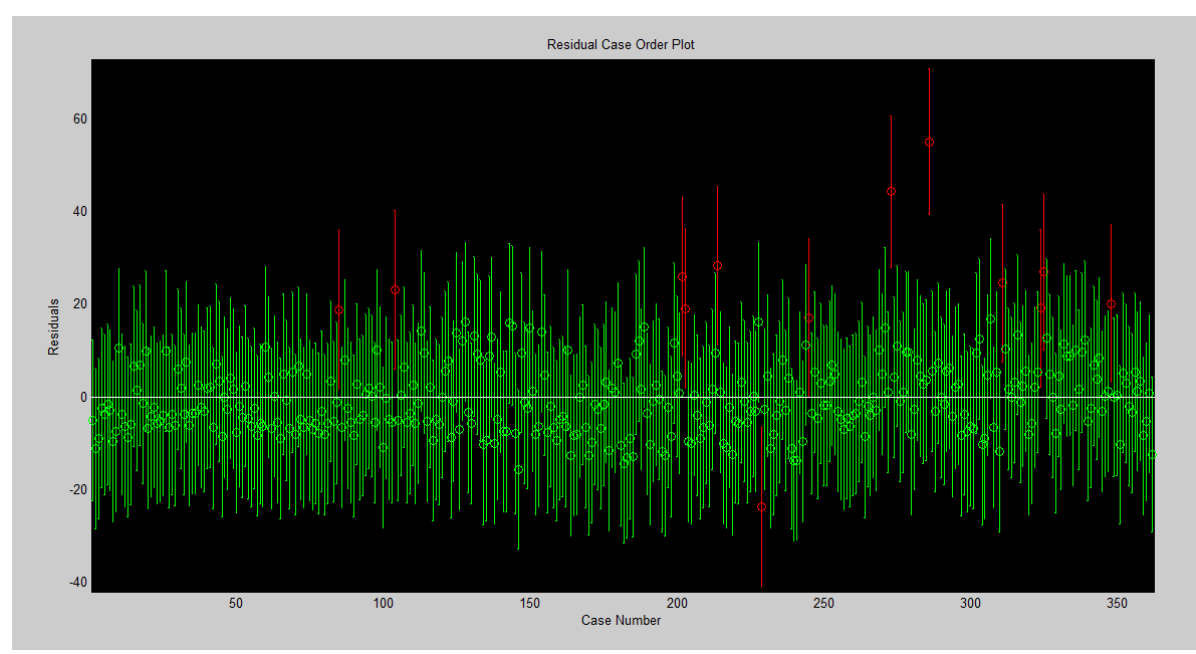

Figure 2. Relationship between PM2.5, PM10 and AQI

Published by Francis Academic Press, UK

$-116-$ 
Academic Journal of Computing \& Information Science

ISSN 2616-5775 Vol. 3, Issue 1: 114-121, DOI: 10.25236/AJCIS.2020.030112

For the sake of the strictness of the results, we use SPSS software to test the above results. The results show that the linear relationship between PM2.5 and PM10 is significant, and there is a linear relationship between PM2.5 and other pollutants such as NO2, SO2 and CO from industrial production. See figures 3 to 5 below .

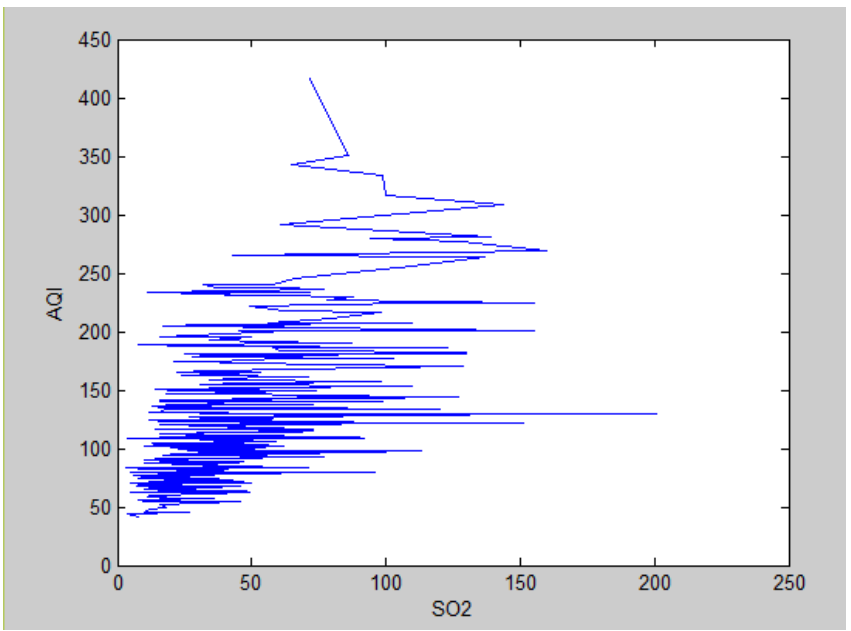

Figure 3. Relationship between SO2 and AQI

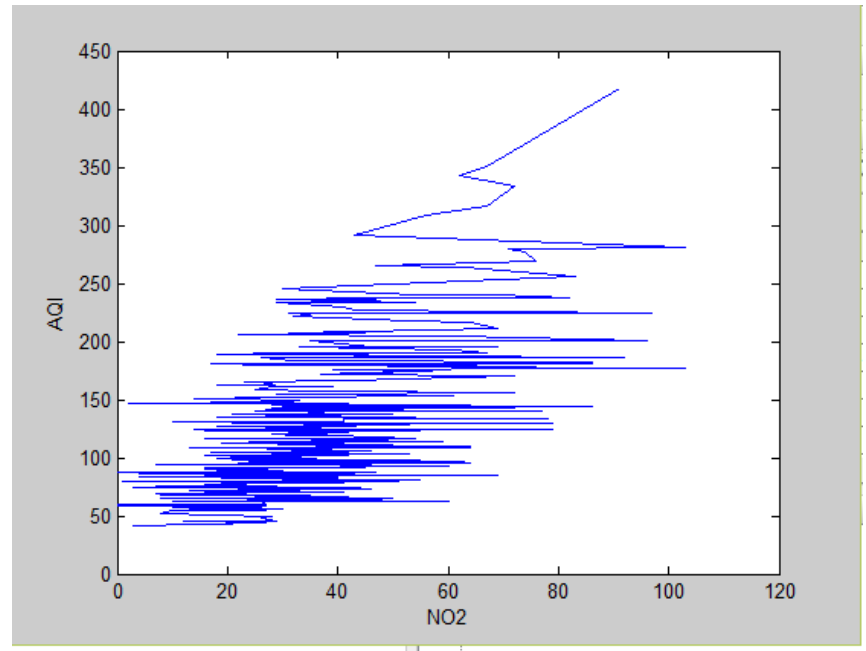

Figure 4. Relationship between NO2 and AQI

Published by Francis Academic Press, UK 


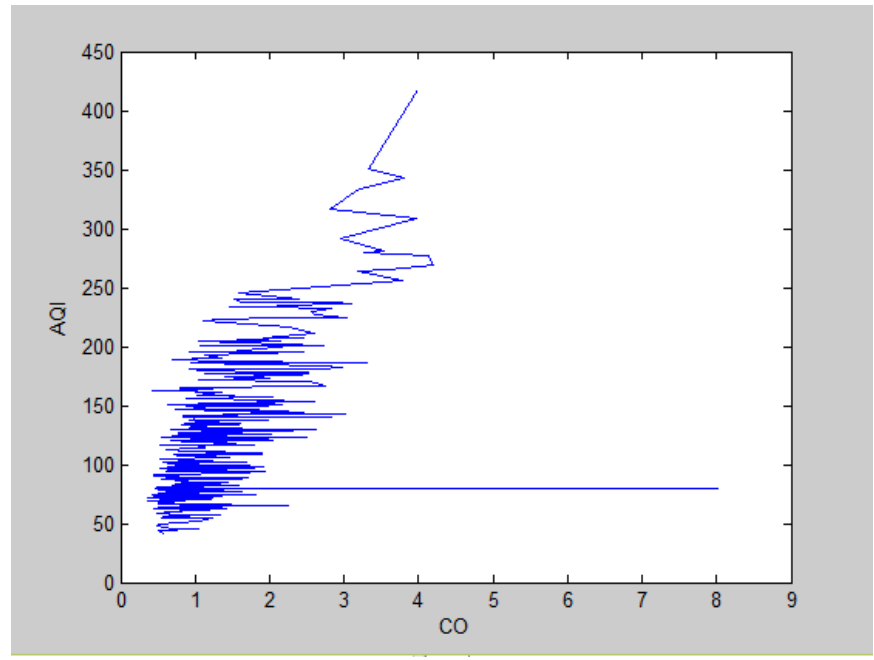

Figure 5. Relationship between $C O$ and AQI

\subsection{Environment and economic development}

The relationship between economic development and environmental protection, in the final analysis, is the relationship between man and nature. The essence of solving environmental problems is how to deal with the relationship between human and nature, human and human, economic development and environmental protection. In the process of the development of human society, from the harmony between man and nature in ancient times, to the conquest and confrontation during the modern industrial revolution, to the conscious adjustment in modern times, to the establishment of a modern civilization in which man and nature live in harmony is an objective reflection of the contradictory movement of economic development and environmental protection and the law of unity. Correctly handling the relationship between environment and development can promote each other and achieve the coordinated development of economy and environment. Nowadays, green economy and circular economy have become the symbol of the new century. It is an inevitable trend of economic development to promote the adjustment of economic structure with environmental protection. To protect the environment is to protect productivity, and to improve the environment is to develop productivity. Therefore, how to coordinate the relationship between environment and economy, and how to build a modern civilization in which man and nature live harmoniously are the key points to adhere to the basic national policy of environmental protection.

There is a contradiction and unity between environmental protection and economic development village: blind pursuit of economic growth will result in serious damage to the environment and resources, thus affecting the economic development itself, while rational use of natural resources, economic development

Published by Francis Academic Press, UK 
Academic Journal of Computing \& Information Science

ISSN 2616-5775 Vol. 3, Issue 1: 114-121, DOI: 10.25236/AJCIS.2020.030112

within the limits of environmental carrying capacity, as well as the accumulation of funds and improvement of technology to promote environmental protection. For developing countries, it is not one-sided. It is emphasized that either party and the two must be coordinated in order to achieve sustained economic development and maintain a good ecological environment, that is, to achieve sustainable development.

\section{Countermeasure research}

\subsection{Set up ideas and popularize education}

Set up and implement the scientific concept of economic development and advocate the "people-oriented" concept of political achievements. At present, GDP is the most important quantitative index to measure the economic development level and political achievements of a region. This value has a certain evaluation significance and value, and can reflect the economic development of a region or country in a quantitative form.

However, this index can not reflect whether economic development will cause pollution to the environment or whether economic development can comprehensively improve the happiness index of ordinary people. For example, the GDP value of some regions remains high, but the serious environmental pollution makes the ordinary people miserable.

In view of these realities, how to establish and implement a scientific concept of economic development and promote the "people-oriented" concept of political achievements is an important practical reform measure related to the people's livelihood.

\subsection{Improve and strengthen the legal system}

To further improve the relevant laws and regulations of environmental protection, criminal legislation can be considered. Environmental protection law of the people's Republic of China was formulated in 1979 and revised in 1989.

The wheels of the $\mathrm{s}$ are rolling forward. China's economic development is changing with each passing day. There are many new contradictions. Conflict points are emerging, especially the major environmental pollution based on new technology in foreign countries.

In many aspects, the relevant laws and regulations of environmental protection need to be further improved, especially for major environmental pollution related to the national economy and people's livelihood, criminal legislation can be considered to make an example.

Establish and improve the official channels and methods of environmental information release. We should correctly treat environmental information in a fair, open and transparent way, so that ordinary people can have sufficient channels to

Published by Francis Academic Press, UK 
Academic Journal of Computing \& Information Science

ISSN 2616-5775 Vol. 3, Issue 1: 114-121, DOI: 10.25236/AJCIS.2020.030112

obtain positive information. In the existing environmental laws and regulations, the right of participation, the right to know, the right to supervise, the right to sue and the right to know of the general public have not been institutionalized, systematized, integrated, explicit and specific.

Based on this, there is a large space for further improvement in environmental protection laws and regulations. In addition, private or unofficial environmental protection organizations may be encouraged to give appropriate. When strict management and correct guidance.

\subsection{Subregional processing}

In the context of rapid economic development in the eastern region, we should increase investment in environmental governance, strengthen environmental protection, and promote high-quality and all-round economic development.

Since the reform and opening up, the eastern region has developed rapidly, forming the Yangtze River Delta economic circle and the Pearl River Delta economic circle. In addition, in recent years, the population aggregation effect of "Peacock Flying Southeast" has become more and more significant. The rapid development of economy and the increasing population also lead to the aggravation of environmental pollution, especially the serious water pollution. Under the condition of more developed economy, it has economic basis to increase the investment in environmental protection and restoration.

In the eastern region, it is feasible to realize the harmonious and sustainable development of ecological environment civilization, economic development and population growth. If so, there will be a better social picture with a virtuous circle. Under the condition of relatively large pollution, the central region should give full play to its scientific and technological advantages and adjust its economic structure appropriately.

The motive of economic development is an important reason for the serious pollution in the central region. To a certain extent, the industrial structure of the central region can be said to be unbalanced and unreasonable. The secondary industry accounts for a large proportion and has a heavy degree of industrialization. Therefore, it is of great significance to adjust the economic structure and give full play to the advantages of science and technology without affecting the economic development.

In the western and northeastern regions with relatively light pollution, we should give full play to the regional characteristics, reduce the outflow of population and tap the demographic dividend.

\section{Acknowledgements}

This paper is supported by the Philosophy and Social Science Research Program in Heilongjiang Province (No.18TJD364).

Published by Francis Academic Press, UK 
Academic Journal of Computing \& Information Science

ISSN 2616-5775 Vol. 3, Issue 1: 114-121, DOI: 10.25236/AJCIS.2020.030112

\section{References}

[1] Brian R, Co Peland and M. Seott Taylor(1994). Is Free Trade Good for the Environment. American. Eeon. Rev, Vol.2, p.152-157.

[2] Matthew A. Cole and Per G (2009). Fredrikssonn: Institutionalized pollution havens. Ecological Economics, Vol.68, p.1239-1256.

[3] Carol Mc Ausland and Daniel L. Millimet(2013). Do national borders matter intranational trade, international trade, and the environment. Journal of Environmental Economics and Management, Vol.65,p.411-437.

[4] Ghanem, D. and Zhang, J (2014). 'Effortless perfection' Do Chinese cities manipulate air pollution data?. Journal of Environmental Economics and Management, Vol.68, p.203-225.

[5] Haddad M A(2015). Increasing Environmental Performance in a Context of Low Governmental Enforcement: Evidence From China. Journal of Environment and Development, Vol.24, p.3-25.

[6] Information on: http://www.stats.gov.cn/tjsj/ndsj/

Published by Francis Academic Press, UK 